\title{
Infrared Radiation Detection Using Fiber Bragg Grating
}

\author{
Jean-Michel Renoirt, Christophe Caucheteur, \\ Marjorie Olivier, Patrice Mégret and Marc Debliquy \\ University of Mons, Faculty of Engineering, Mons,
} Belgium

\section{Introduction}

Optical fiber sensors bring to measurement systems all the advantages offered by the optical fiber technology. In particular, their low weight and small dimensions yield non-intrusive capabilities while their immunity against electromagnetic interference leads to usefulness in harsh environments. Among the various optical fiber sensor configurations, fiber Bragg gratings (FBGs) are particularly interesting, especially thanks to their wavelength-encoded response and their inherent multiplexing capability. They can be used to measure static and dynamic perturbations such as temperature (Crunelle et al., 2009; Fernandez-Valdivielso et al., 2002), mechanical strain (Han, 2009; Ho, 2002) and pressure (Sheng et al., 2004). Their association with a sensitive layer converting the measurand into a local stress or a temperature elevation around the FBGs drastically increases the panel of applications.

Among others, gas sensing (Buric et al., 2007; Caucheteur et al., 2008), humidity sensing (Kronenberg et al., 2002; Yeo et al., 2005), salinity (Lu et al., 2008; Men et al., 2008), magnetic field (Davino et al., 2008; Yang et al., 2009) and pH monitoring (Corres et al., 2007) have been recently reported. Based on a similar principle, the association of an absorbing layer to a FBG can be realized for infrared (IR) radiation detection purposes as it has been demonstrated in (Caucheteur, 2010; Renoirt, 2010; Yüksel, 2011). The authors adapted the operating principle of a standard bolometer to the optical fiber in order to benefit from all the advantages of the latter.

Such a configuration is particularly interesting for early fire detection over long distances (Sivathanu, 1997). This kind of sensor presents significant advantages over smoke and heat detectors as it can monitor a wide area and can respond in less than a few seconds.

This chapter describes a fibered bolometer based on a pair of FBGs. One is covered with an IR-absorbing material while the other is uncoated and sheltered from the radiation in order to be used as a reference. Both FBGs act the same way as for the classical bolometer. The useful signal is the differential wavelength shift between the coated and the protected FBGs when exposed to IR radiation.

The remaining of the chapter is organized as follows. After a presentation of the usual existing technologies for infrared detection, the sensing principle is presented. Section 4 is dedicated to the sensor fabrication and the different designs, while section 5 presents the experimental 
results. In section 6, the modeling of the sensor is described for different configurations. The experimental results are compared to the modeling and discussed. Finally, section 7 draws some conclusions.

\section{Existing systems}

In this section, the main existing technologies for the infrared radiation detection are described (Gaussorgues et al., 1996). In Table 1, existing technologies are classified following their type. A short explanation of the working principle of each detector is given below.

\begin{tabular}{|c|c|c|}
\hline Type & Detector & Spectral response \\
\hline \multirow{5}{*}{$\begin{array}{l}\text { Thermal } \\
\text { Thermal sensors are receivers in } \\
\text { which the light flux is transiomed into } \\
\text { heat by an absorbing process and the } \\
\text { useful signal is the temperature } \\
\text { increase due to absorption. The } \\
\text { temperature increase is transiormed } \\
\text { by different means into an electrical } \\
\text { signal }\end{array}$} & Thermocouple - thermopile & \multirow{5}{*}{$\begin{array}{l}\text { Depends } \\
\text { on window } \\
\text { material }\end{array}$} \\
\hline & Bolometer & \\
\hline & Pneumatic cell & \\
\hline & Pyroelectric detector & \\
\hline & Pyromagnetic detector & \\
\hline \multirow{4}{*}{$\begin{array}{l}\text { Quantum } \\
\text { Detectors in which the signal } \\
\text { corresponds to the measurement of } \\
\text { the direct excitation of particles by the } \\
\text { incident photons }\end{array}$} & Photoconductive type & $\begin{array}{c}\text { PbS: } 1-3.6 \mu \mathrm{m} \\
\text { Plise }: 1.5-5.8 \mu \mathrm{m} \\
\mathrm{InSb}: 2-6 \mu \mathrm{m} \\
\text { HecdTe }: 2-16 \mu \mathrm{m}\end{array}$ \\
\hline & Photovoltaic type & $\begin{array}{c}\mathrm{Ge}: 0.8-1.8 \mu \mathrm{m} \\
\operatorname{InCiaAs}: 0.7-1.7 \mu \mathrm{m} \\
\text { LnSht : } 1-5.5 \mu \mathrm{m}\end{array}$ \\
\hline & Photoemissive type & $\mathrm{AgOCs}: 0.2-1 \mu \mathrm{m}$ \\
\hline & Quantum well type & GiAsGianiAs: $8-12$ y \\
\hline $\begin{array}{l}\text { Charge Coupled Devices } \\
\text { Detectors based on coupled MOS } \\
\text { capacitances structures that allow } \\
\text { imaging }\end{array}$ & IRCCD & 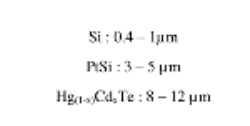 \\
\hline
\end{tabular}

Fig. 1. Summary of the usual systems for infrared radiation detection

\section{Working principles of the different systems}

\section{- Thermal}

- Thermocouple - thermopile: A thermopile converts thermal energy into electrical energy. It is composed of several thermocouples usually connected in series or in parallel in contact with an absorbing material. Thermopiles do not generate a voltage proportional to absolute temperature, but to a local temperature difference or temperature gradient.

- Bolometer: A bolometer measures the power of incident electromagnetic radiation via the heating of an absorbing material with a temperature-dependent electrical resistance.

- Pneumatic cell: Pneumatic cells are based on the measurement of the pressure variation of a well-known mass of gas in a closed chamber. The radiation flux heats the sensitive element inside the chamber, increasing the gas pressure which induces a deformation of a membrane. 
- Pyroelectric detector: Pyroelectric detectors are made of pyroelectric films absorbing the radiation. For these materials, a temperature increase induces electrical charges at the surface. The surface charge density is proportional to the temperature increase. The charges are collected by electrodes transforming the temperature rise in an electric signal. These sensors can only measure variations and not steady radiations. For slowly changing radiation intensity, the pyroelectric film is periodically hidden by a mask inducing a rapidly changing exposure to the radiation.

- Pyromagnetic detector: Pyromagnetic detectors use ferromagnetic materials with permanent magnetization. The magnetization decreases with temperature and becomes equal to zero at the Curie temperature. Below this temperature, a variation of temperature induces a reversible variation of magnetization. The magnetization is measured in a classical magnetic circuit.

\section{- Quantum}

- Photoconductive type: The observed signal is the conductivity increase of a crystal when exposed to radiation. The absorption of radiation, if energetic enough ( $E>E_{\text {gap }}$ of the semiconductor), may induce the creation of electron-hole pairs. The free electrons and holes participate to the current flow in the material when biased. The variation of conductivity is measured using an external source of current.

- Photovoltaic type: Incident photons of the impinging radiation with sufficient energy ( $E>E_{\text {gap }}$ of the semiconductor) may be absorbed in the space charge zone of a p-n junction causing the formation of electron-hole pairs. The electrons and holes will migrate through the junction under the action of the junction field. The resulting current through the junction is proportional to the intensity of the radiation. Photovoltaic detectors behave as energy generators and can give a signal without polarization.

- Photoemissive type: Incident photons of the impinging radiation with sufficient energy may extract electrons from a solid due to the joint effects of incident photons and a static polarization between the solid and a collecting electrode. The resulting current is proportional to the intensity of the radiation.

- Quantum well type: This kind of detector consists in a stacking of materials between two highly doped materials for the electron collection. A bias voltage is applied to bend the energy bands. This is carried out at low temperature (typically 77K). Electrons are trapped in the fundamental state. An incident radiation can induce a transition and electrons go from emitter to collector, leading to a current that can be measured.

\section{- Charge Coupled Devices}

- InfraRed Charge Coupled Devices (IRCCD) : The basic principle of this kind of detector is the following: radiation induces electric charges in a semiconductor. The amount of charges is proportional to the intensity of the radiation. These charges are stored in an isolator element playing the role of a capacitor (MOS structure). These structures are placed in arrays. The generated charges are then transferred by an electric field applied successively to the next similar element. Collection of all the charges on the same array is made by a unique electrode and is treated as a video signal. A complete device is composed of a large number of such arrays defining a 2 dimensional structure consisting of pixels. This system is used for processing images.

All these systems give an electrical signal output and yield point detection while the presented system produces a purely optical signal and can provide quasi-distributed detection. 


\section{Sensing principle}

\subsection{Basic principle}

The emission spectrum of a hot source, for instance a fire, can be approximated by Planck's law giving the spectral radiance of a black body as a function of the wavelength for a given temperature:

$$
B_{\lambda, T}=\frac{2 h c^{2}}{\lambda^{5}} \frac{1}{e^{\frac{h c}{\lambda k T}}-1}
$$

where $B_{\lambda, T}$ is the spectral radiance, $h$ is Planck's constant $\left(6.62 \times 10^{-34} \mathrm{Js}\right), c$ the speed of light in vacuum, $k$ the Boltzmann constant $\left(1.38 \times 10^{-23} \mathrm{~J} / \mathrm{K}\right)$ and $T$ the absolute temperature of the black body. Fig. 2a depicts the radiance spectrum obtained from Equation 1 for different temperatures. To obtain a plot independent of the total radiance, each curve has been normalized (at each temperature, values are divided by the maximum radiance for this temperature). Therefore, it is easy to compare the effect of a higher temperature on the spectral distribution.

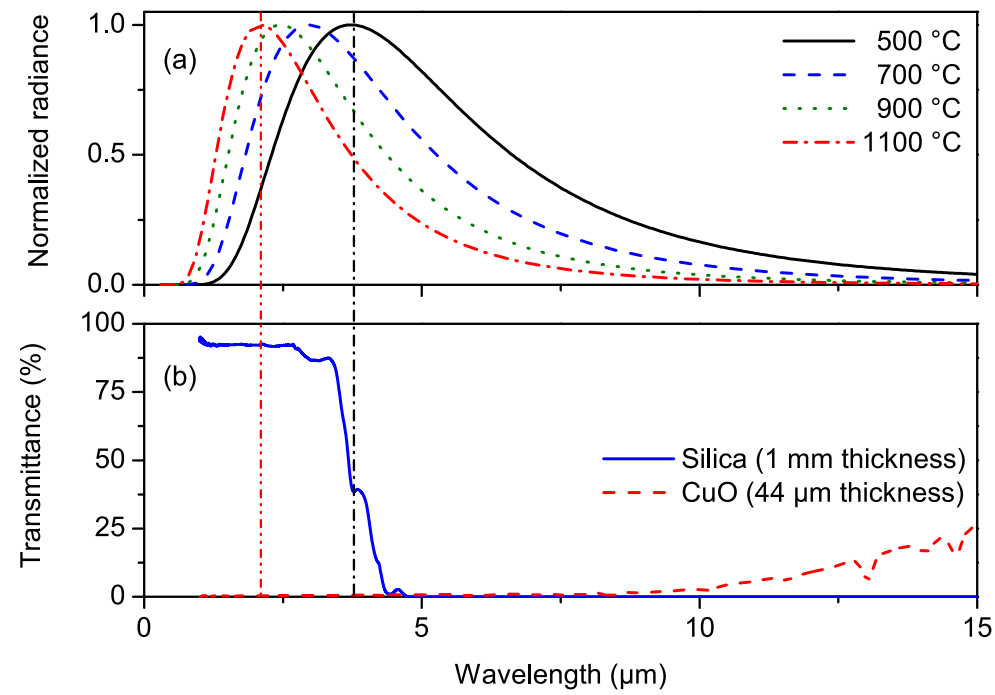

Fig. 2. (a) Spectral radiance at different temperatures, (b) silica - $\mathrm{CuO}$ transmittance spectra.

On this graph, a maximum is observed at around $5 \mu \mathrm{m}$ for $500{ }^{\circ} \mathrm{C}$ while the maximum is observed at $2 \mu \mathrm{m}$ for $1100{ }^{\circ} \mathrm{C}$. A higher temperature has a narrower distribution centered on a lower wavelength. The major part of the spectrum emitted by hot spots and fires lies in the range from $0.8 \mu \mathrm{m}$ to $15 \mu \mathrm{m}$.

Since silica absorbs part of the IR radiation, an uncoated FBG could be used as an IR sensor. However, it will have a weak response because silica absorbs only for wavelengths longer than $4 \mu \mathrm{m}$. The transmittance spectrum of silica (thickness: $1 \mathrm{~mm}$ ) is shown on Fig. 2b. Silica can be seen as a low-pass filter in wavelength. Below $4 \mu \mathrm{m}$, silica is almost transparent (transmittance is not equal to $100 \%$ because part of the incident beam is reflected by the material) and 
very absorbing above $4 \mu \mathrm{m}$. It means that for high temperature sources the signal will be underestimated. Therefore, in order to cover the whole wavelength range of the radiation and to yield a sensitivity independent of the source temperature, an additional coating is needed to absorb radiation at shorter wavelengths. The chosen coating is a layer of copper(II) oxide. Copper(II) oxide is a black compound and is well-known for its good absorbing properties in the near IR-domain (this material is used in solar panels). The transmittance spectrum for a layer of $44 \mu \mathrm{m} \mathrm{CuO}$ encapsulated in a polymer is displayed in Fig. $2 \mathrm{~b}$.

\subsection{Operating principle of FBGs sensors}

Fiber Bragg gratings sensors are often used for temperature and strain measurements (Othonos, 1999). A FBG is a periodic and permanent modulation of the core refractive index along the fiber axis (Fig. 3). In its simplest form, it acts as a mirror, selective in wavelength around a resonance wavelength given by the following relationship:

$$
\lambda_{B}=2 \Lambda n_{\mathrm{eff}}
$$

where $n_{\text {eff }}$ is the effective refractive index of the fiber core mode at the Bragg wavelength and $\Lambda$ the grating period. To obtain Bragg wavelengths centered in the telecommunication window around $1.55 \mu \mathrm{m}$, the order of magnitude of $\Lambda$ is $500 \mathrm{~nm}$.

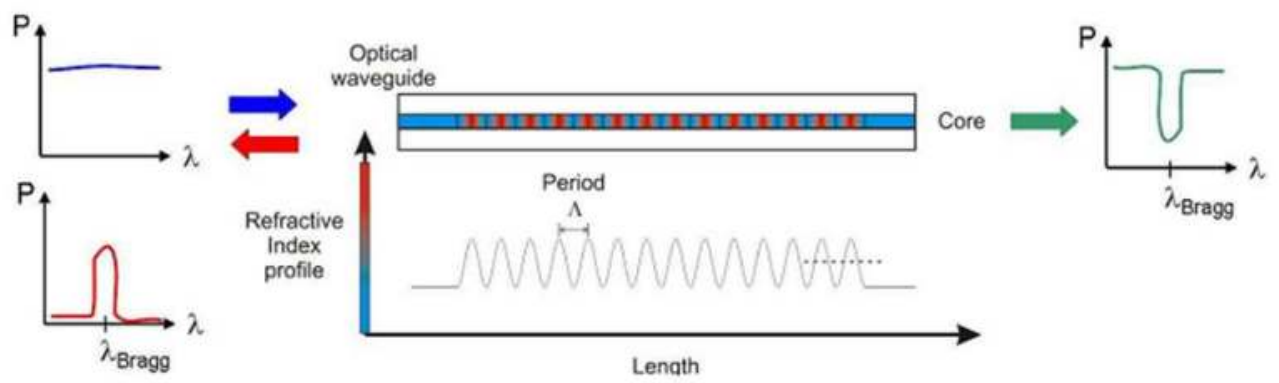

Fig. 3. Principle of a fiber Bragg grating.

Temperature and strain modify both $n_{\text {eff }}$ and $\Lambda$ and as a result, change the Bragg wavelength. A specific packaging can be used to isolate the strain effect in a way that the sensor is only sensitive to temperature. The average Bragg wavelength-shift at $1550 \mathrm{~nm}$ due to a temperature change is about $10 \mathrm{pm} /{ }^{\circ} \mathrm{C}$. In the presented sensor configuration, a pair of gratings is used, one coated and the other one protected from the outside radiation. The temperature change is measured by the shift in the Bragg wavelengths. The wavelength of the protected grating depends on the room temperature change while the wavelength of the coated grating depends on the infrared radiation and the room temperature fluctuations. The measurement of the differential shift between the two grating wavelengths provides the signal corresponding to the temperature rise due to the infrared radiation. Typical spectra for both cases (with and without IR radiation) are sketched in Fig. 4.

The useful signal is the differential Bragg wavelength shift between the coated and the protected gratings:

$$
\Delta \lambda_{B}=\lambda_{B_{2}^{\prime}}-\lambda_{B_{1}^{\prime}}-\Delta
$$




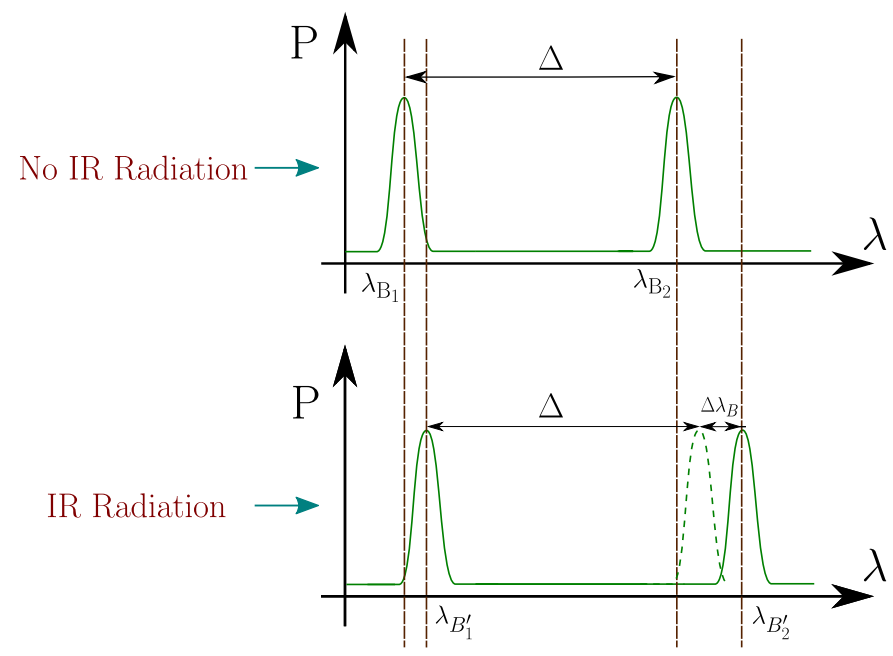

Fig. 4. Optical reflected spectra of a pair of gratings.

where $\Delta$ is the difference in Bragg wavelengths between the two gratings when there is no radiation $\left(\Delta=\lambda_{B_{2}}-\lambda_{B_{1}}\right)$.

\subsection{Sensitivity}

The sensitivity $\Sigma_{T}$ of the sensor is defined in terms of temperature rise for a given radiation flux $f$ :

$$
\Sigma_{T}=\frac{\Delta T}{f}
$$

where $\Delta T$ is the difference between fiber and room temperature $\left({ }^{\circ} \mathrm{C}\right)$ and $f$ the total infrared flux on the sensor $\left(\mathrm{W} / \mathrm{m}^{2}\right)$. The sensitivity $\Sigma_{\lambda}$ can also be defined in terms of wavelength shift for a given heat flux and is then given by:

$$
\Sigma_{\lambda}=\frac{\Delta \lambda_{B}}{f}
$$

\subsection{Sensitivity enhancement}

The sensitivity for this sensor can be easily enhanced using a glass capillary around the coated grating. It creates a greenhouse effect around the fiber and therefore, for a given radiation power, the temperature rise is higher, resulting in an increased sensitivity. Indeed, infrared radiation below $4 \mu \mathrm{m}$ passes through the glass tube and are absorbed by the CuO-layer. The CuO-coated fiber will reemit at lower wavelengths but this radiation is confined in the capillary because glass absorbs radiation above $4 \mu \mathrm{m}$. As a result, the glass tube absorbs radiation with wavelengths above $4 \mu \mathrm{m}$ not only coming from the source but also from the fiber. The glass tube exchanges heat with the coated grating by a radiation process and increases the fiber temperature for a given radiating flux. It has a strong effect on the sensitivity of the sensor. 


\section{Sensor fabrication}

\subsection{Bragg grating and coating}

The gratings were inscribed on a standard germanium-doped silica fiber according to classical procedures. The two gratings were $10 \mathrm{~cm}$ separated, the reference grating was centered at $1528 \mathrm{~nm}$ and the coated grating at $1533 \mathrm{~nm}$. The fiber was coated with a $\mathrm{CuO}$ loaded polymer by dip coating followed by drying at $110^{\circ} \mathrm{C}$ during $5 \mathrm{~min}$ and UV-curing for $30 \mathrm{~s}$. This method gives a good absorbing layer (thickness: $44 \mu \mathrm{m}$ ) (Fig. 2b) with good adhesion on the fiber. The polymer matrix leads to a thicker layer with a very short deposition time $(<5 \mathrm{~min})$ compared to other deposition processes (sputtering ... ). Moreover the coating has a higher roughness, decreasing reflection and as a consequence, increasing absorption.

\subsection{Glass capillary and packaging}

To improve the sensor response, a thin glass tube (outer diameter $\approx 1 \mathrm{~mm}$ ) was put around the CuO-coated FBG. To ensure good measurements and good performances, care was taken to place the fiber perfectly in the center of the capillary. If the sensor would be in contact with the capillary, a thermal bridge would be established between the capillary and the fiber, considerably modifying the response of the sensor. A packaging is needed to protect the uncoated grating from the outside radiation. It is fundamental to have a stable reference in order to eliminate room temperature fluctuations. This packaging can be advantageously tailored around the double FBG to improve the sensitivity (Fig. 5). The packaging is metallic (aluminum) and acts as a mirror. Furthermore, by concentrating the radiation on the fiber, it allows to reduce the minimal incident intensity which can be detected. Although the parabolic shape is the best one to concentrate the radiation on the sensor, experiments have been done with a circular aluminum tube. Aluminum is a good reflector for infrared radiation (for wavelengths $>2 \mu \mathrm{m}$ the reflectivity is greater than $97 \%$ ); it isolates the second grating from the outside infrared radiation and concentrates radiation on the copper oxide coated grating. Figure 5 shows an example of such a packaging (aluminum tube of $20 \mathrm{~mm}$ outer diameter and $17 \mathrm{~mm}$ inner diameter). A rectangular aperture is made to form a cylindrical mirror (Fig. 5). As in the case of the glass tube, the aluminum tube diameter can be modified. A larger tube can harvest and concentrate more radiation but the advantages (low weight, small dimensions) of optical fiber are lost.

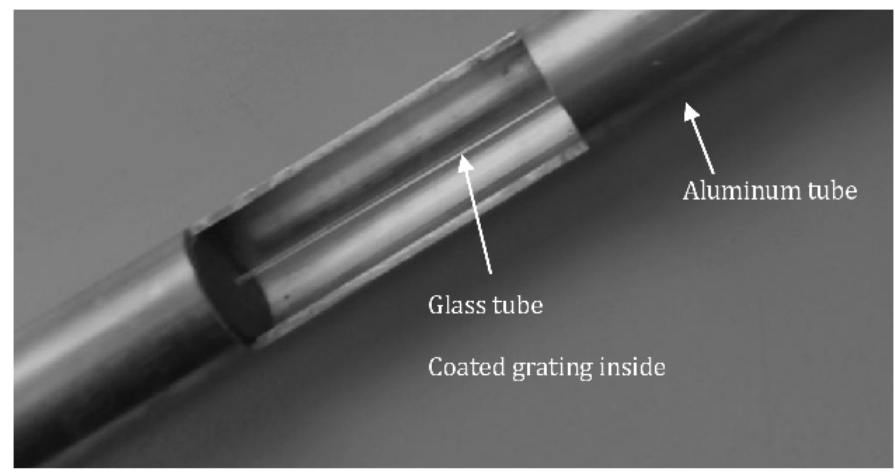

Fig. 5. Packaging made of an aluminum tube and the coated FBG inside the capillary tubing. 


\section{Sensitivity measurements}

\subsection{Experimental set-up}

In this section, the experimental set-up and the measurement processes are explained. Fig. 6 presents a sketch of the experimental set-up. An ASE (Amplified Spontaneous Emission) source covering the $\mathrm{C}+\mathrm{L}$ bands $(1525 \mathrm{~nm}-1610 \mathrm{~nm})$ and an optical spectrum analyzer (OSA) ANDO AQ6317C are used to collect the reflected spectrum of the double grating configuration. The heat source is provided by a furnace (Edouard Defrance, inner volume $\left.3.61\left(\mathrm{~T}_{\text {room }}-1100{ }^{\circ} \mathrm{C}\right)\right)$. In order to measure the incident flux, a radiant flux sensor (Captec Enterprise, $\left.10 \times 10 \mathrm{~mm}^{2}, 0.438 \mu \mathrm{V} /\left(\mathrm{W} / \mathrm{m}^{2}\right)\right)$ was put close to the fiber. A simple way to modify the incident power is to put the sensor at different distances from the heat source. The infrared radiation flux decreases with the square of the distance to the source. The temperature has also an important effect on the flux value. When increasing the furnace temperature, the spectrum of the incident radiation is changed. From the reflected spectrum measurement, the two Bragg wavelengths can be obtained.

The difference between both wavelengths is nearly proportional to the IR radiation absorbed by the sensor. All the gratings were coated with copper oxide encapsulated into polymer deposited on a length of $5 \mathrm{~cm}$. Other parameters can significantly influence the sensitivity: diameter and thickness of the capillary tubing and thickness of the copper oxide coating. Modeling of the sensor surrounded by the glass capillary was carried out in order to understand the complete mechanism of the sensor response and optimize it by changing relevant parameters (see section 6). Another key point, for all experiments, is to ensure that the FBG sensor is not strained. The strain can indeed vary with time, leading to a wrong measurement of the resonance shift. FBGs sensors are very sensitive to strain. Therefore, the sensor and capillary must be carefully designed to allow natural expansion of the fiber without supplementary strain. For each measurement, the temperature of the furnace was stabilized at the target value. The furnace door was opened and the measurement time was between 15 and $45 \mathrm{~s}$.

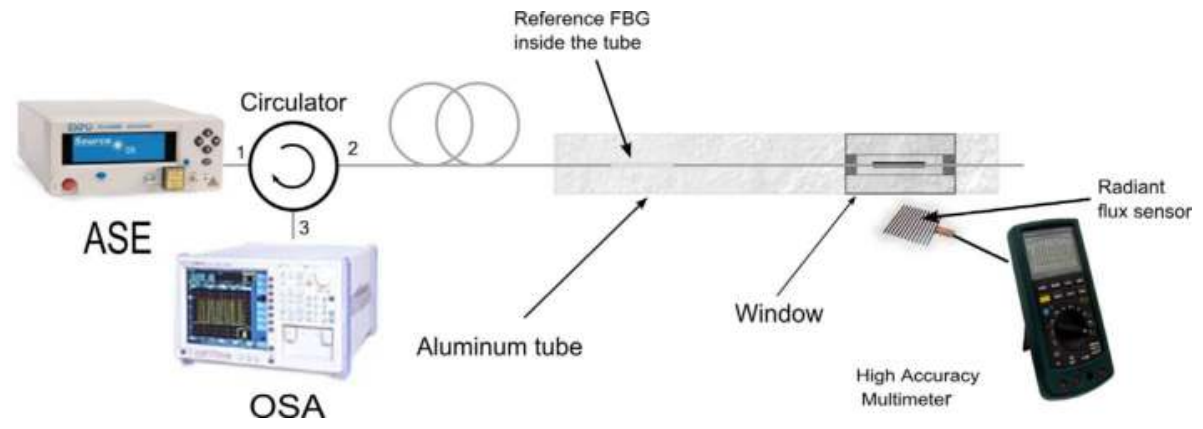

Fig. 6. Sketch of the experimental set-up.

\subsection{Results}

The following paragraph presents the experimental results conducted with three sensor configurations: a $\mathrm{CuO}$ coated fiber, a fiber inserted into a glass capillary and finally, fiber and capillary put in a reflecting packaging. In order to follow the influence of the source temperature, the sensitivities were measured at 4 temperatures: 500, 700, 900 and $1100{ }^{\circ} \mathrm{C}$. 
In the case of the first configuration (fiber without capillary), Fig. 7 shows the response (Bragg wavelength shift) as a function of the incident flux when the furnace temperature is kept at 700 and $900{ }^{\circ} \mathrm{C}$. The response is linear with the incident flux. The sensitivity at $700{ }^{\circ} \mathrm{C}$ is about $8 \times 10^{-3} \mathrm{pm} /\left(\mathrm{W} / \mathrm{m}^{2}\right)$ which corresponds to $8 \times 10^{-4}{ }^{\circ} \mathrm{C} /\left(\mathrm{W} / \mathrm{m}^{2}\right)$. The resolution of the OSA used for the experiments is $10 \mathrm{pm}$.

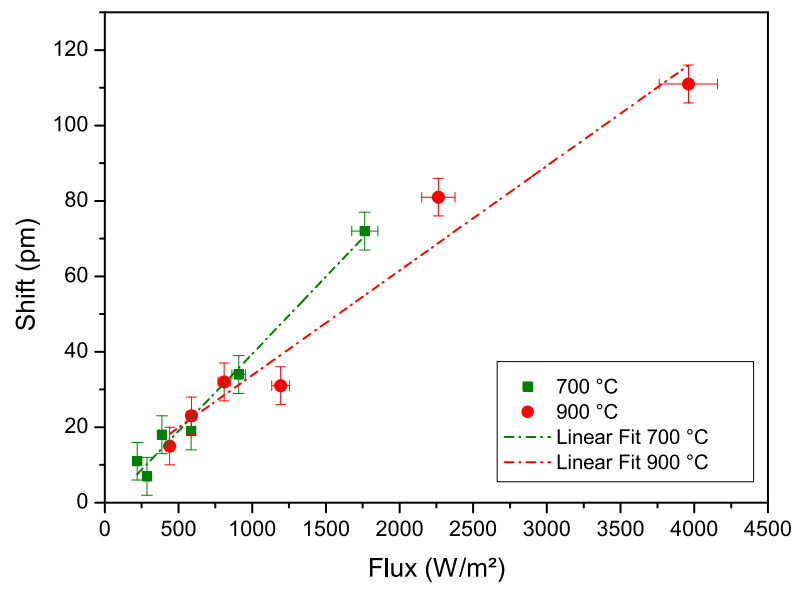

Fig. 7. Shift of the Bragg wavelength for a furnace temperature of 700 and $900{ }^{\circ} \mathrm{C}$, without capillary tubing on the grating.

Results at 500, 900 and $1100{ }^{\circ} \mathrm{C}$ are similar, with respectively a slope of $12 \times 10^{-3}, 6 \times 10^{-3}$ and $4 \times 10^{-3} \mathrm{pm} /\left(\mathrm{W} / \mathrm{m}^{2}\right)$.

For the second configuration, with gratings surrounded by a glass capillary tube, the sensitivity is, as expected, higher but the influence of the furnace temperature is still substantial. Results for the grating covered with capillary tubing are shown in Fig. 8.

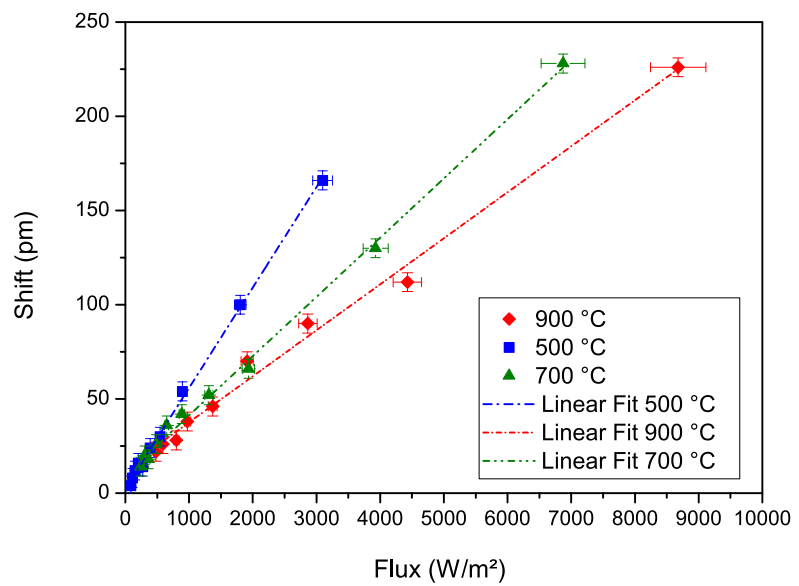

Fig. 8. Shift of the Bragg wavelength for a fiber surrounded by a glass capillary for different temperatures. 
Finally, in the case of the whole packaging (Fig. 9), the sensitivity $\Sigma_{\lambda}$ decreases again when the source temperature rises. At $500{ }^{\circ} \mathrm{C}, \Sigma_{\lambda}$ is around $0.11 \mathrm{pm} /\left(\mathrm{W} / \mathrm{m}^{2}\right)$ and is about $0.05 \mathrm{pm} /\left(\mathrm{W} / \mathrm{m}^{2}\right)$ at $1100{ }^{\circ} \mathrm{C}$. The influence of the source temperature on the sensitivity can be reduced by adding a $\mathrm{CuO}$ layer on the capillary tube itself.

For the sake of comparison, table 1 presents an overview of the results for the different tested temperatures and sensor configurations.

\begin{tabular}{|c|c|c|c|c|}
\hline $10^{-3} \mathrm{pm} /\left(\mathrm{W} /{ }^{2} \mathrm{~m}\right)$ & $500{ }^{\circ} \mathrm{C}$ & $700{ }^{\circ} \mathrm{C}$ & $900{ }^{\circ} \mathrm{C}$ & $1100{ }^{\circ} \mathrm{C}$ \\
\hline Without packaging & 12 & 8 & 6 & 4 \\
With capillary & 50 & 31 & 25 & 20 \\
Whole packaging & 110 & 100 & 75 & 50 \\
\hline
\end{tabular}

Table 1. Sensitivity for different furnace temperatures and sensors configurations

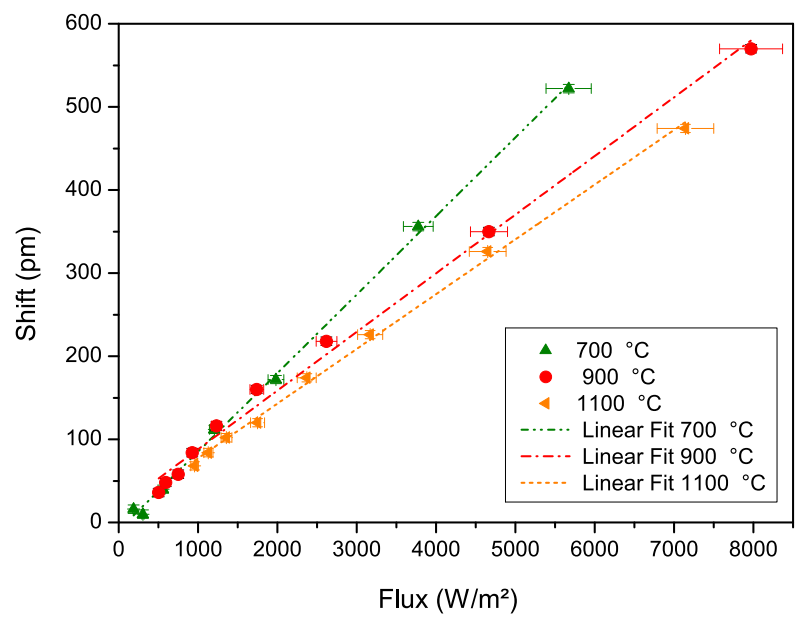

Fig. 9. Shift of the Bragg wavelength for different temperatures, with glass and aluminum tubes.

The experimental results show that it is possible to achieve an IR detection system with a good sensitivity with fiber Bragg gratings. For a given source temperature, the sensor shows a linear behavior according to the flux intensity. However, the sensitivity of the sensor is still influenced by the source temperature. The sensitivity of the sensor is higher at lower temperature. The most important property in the perspective of early fire detection is a low threshold for alarm. The threshold is in the range of the $\mathrm{kW} / \mathrm{m}^{2}$.

The first two configurations described above are theoretically modeled in the next section.

\section{Theoretical response of the sensor}

Considering the fact that a grating has a temperature sensitivity of the order of $10 \mathrm{pm} /{ }^{\circ} \mathrm{C}$, it is possible to compute and model the behavior of the sensor under a given infrared radiation flux. Indeed, the temperature of the fiber under the infrared radiation and so the Bragg wavelength resonance shift is the result of the balance between the thermal losses and incident energy absorbed energy. 
Firstly, the simple case of a fiber covered with $\mathrm{CuO}$ without protection is discussed.

\subsection{Case 1: fiber with absorbing coating alone}

In Fig. 10, the different losses and energy fluxes are displayed in the case of a fiber without protection. Let us consider $\mathrm{L}$ the length of the exposed zone of the fiber ( $\mathrm{L}$ is typically a few $\mathrm{cm})$. The total energy absorbed by the section of length $L\left(\Phi_{\mathrm{abs}}\right)$ is equal to the losses of the same section due to convection $\left(\Phi_{\text {conv }}\right)$, radiation with the ambient $\left(\Phi_{\text {rad }}\right)$ and conductivity along the fiber ( $\left.\Phi_{\text {cond }}\right)$. The temperature of the exposed section is supposed to be uniform. At thermal equilibrium, the fiber will stabilize at a temperature higher than the room temperature according to the following thermal balance (Equation 6):

$$
\Phi_{\mathrm{abs}}=\Phi_{\mathrm{conv}}+\Phi_{\mathrm{rad}}+\Phi_{\mathrm{cond}}
$$

The positive contribution to the balance $\left(\Phi_{\mathrm{abs}}\right)$ comes from the incident infrared flux of the hot spot. The absorption properties of the materials constituting the sensor (which depend on the wavelengths of the incident radiation) must be taken into account. The losses can be divided into 3 parts:

- $\Phi_{\text {conv }}$ results from the exchanges with ambient air due to convection.

- $\Phi_{\text {rad }}$ comes from heat exchanges due to radiation between the fiber and the ambient.

- $\Phi_{\text {cond }}$ is due to thermal conduction along the axis of the fiber. This term is small compared to the first two because thermal conductivity of silica is small.

All these terms depend on the temperature of the fiber.

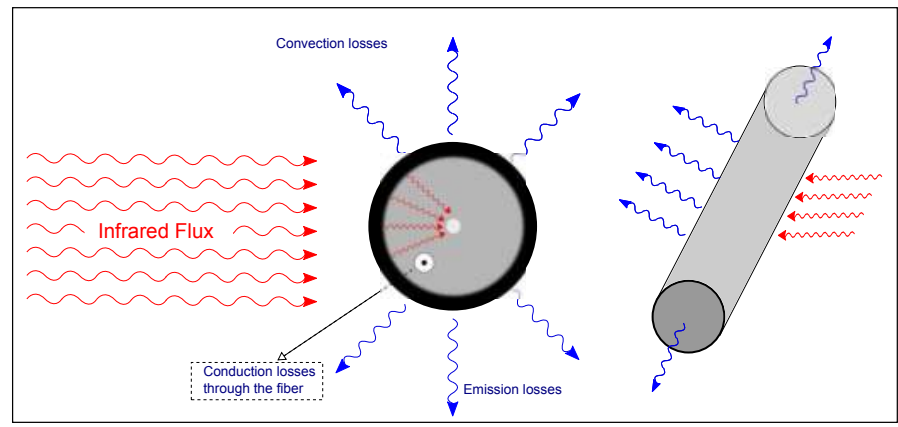

Fig. 10. Thermal exchanges existing on the optical fiber.

As the diameter of the fiber is very small, it can be shown that there is no radial significant gradient inside the fiber and the temperature is considered as uniform in the exposed zone. Indeed, Biot's number is defined by:

$$
B i=\frac{K \cdot D}{\kappa_{\text {silica }}}
$$

where $K$ is the exchange coefficient resulting from convection and radiation (typically $\left.50 \mathrm{~W} /\left(\mathrm{m}^{2} \mathrm{~K}\right)\right), D$ is the diameter of the fiber including the coating $(200 \mu \mathrm{m})$ and $\kappa_{\text {silica }}$ the thermal conductivity of silica $(\approx 1 \mathrm{~W} /(\mathrm{mK}))$. In our case, Biot's number is approximately equal to $10^{-2}$. For a solid in contact with a fluid and exchanging heat with the fluid, Biot's number represents the ratio of the heat transfer resistance through the solid and the heat 
transfer resistance through the surrounding fluid (Perry, 1984). When Biot's number is small $(<0.1)$, it means that the main resistance is due to the exchange with the fluid and so the radial temperature gradient in the solid can be neglected.

The different terms in Equation 6 are detailed in the following paragraphs.

\subsubsection{Absorption of the fiber}

The fraction of energy absorbed by the fiber and its coating is given by :

$$
\Phi_{\mathrm{abs}}=K_{\mathrm{abs}} R_{s} L f
$$

$K_{\mathrm{abs}}$ represents the global absorption coefficient. In practice, $0 \leq K_{\mathrm{abs}} \leq 2$. The case $K_{\mathrm{abs}}=0$ corresponds to a totally transparent material, while the case $K_{\mathrm{abs}}=2$ describes a completely absorbed radiation, because the latter comes from one direction.

$R_{s}$ is the radius of the fiber including the coating (in our case, $R_{s}=R_{f}+e_{\mathrm{CuO}}$ ) where $e_{\mathrm{CuO}}$ is the thickness of the coating.

$K_{\mathrm{abs}}$ can be computed by a simple model using the Beer-Lambert law and assuming the spectral intensity to follow Planck's law. Transmission of the material is given by the Beer-Lambert law:

$$
\mathrm{T}_{\lambda}=\frac{\mathrm{I}_{\lambda}}{\mathrm{I}_{0 \lambda}}=\mathrm{e}^{-\alpha_{\lambda} d}
$$

where $\mathrm{I}_{0 \lambda}$ is the intensity of the radiation at wavelength $\lambda, \mathrm{I}_{\lambda}$ is the intensity transmitted through the absorbing material, $d$ is the distance travelled in the material and $\alpha_{\lambda}$ is the absorption coefficient that depends on the wavelength for a given material.

The fraction of absorbed energy after traveling a length $d$ is given for each wavelength by :

$$
\mathrm{A}_{\lambda}=\left(1-\mathrm{R}_{\lambda}\right)\left(1-\mathrm{e}^{-\alpha_{\lambda} d}\right)
$$

with $R_{\lambda}$ being the reflection coefficient of the material. The total absorbed energy is obtained by integration over all wavelengths.

The optical properties of the absorbing material ( $\mathrm{CuO}$ dispersed in a polymer matrix) were experimentally determined by spectroscopy as it presents a complex behavior. For fused silica, data from the literature (Desvignes (1991)) were used. From these data, the absorption coefficients as a function of the wavelength were extracted (cf. Fig. 11 and 12).

To determine $K_{\mathrm{abs}}$, the fiber is mathematically cut in slices (cf. Fig. 13) and Equation 10 is used on each slice. Absorption of the coating and absorption of the fiber are then added.

Using Equation 10 for coating and fiber, the absorbed radiation is given by Equation 11 for the portion of the coating/fiber between $\theta$ and $\theta+d \theta$. By integrating from $-\pi / 2$ to $+\pi / 2$, we obtain the whole absorption of the fiber (Fig. 11).

Remark: As the absorption coefficient of the material is quite large, the secondary reflections at the back are neglected in this model.

$$
\begin{aligned}
\Phi_{\mathrm{abs}}=R_{f} L f & \int_{\lambda=0}^{\lambda=\infty} \int_{\theta=-\frac{\pi}{2}}^{\theta=\frac{\pi}{2}} \cos (\theta) \frac{f_{\lambda}}{f}\left(\mathrm{e}^{-\alpha_{\lambda}^{c} e(\theta)}\right. \\
& {\left.\left[1-\mathrm{e}^{-2 \alpha_{\lambda}^{v} R_{f} \cos (\theta)}+\left(1-\mathrm{e}^{-\alpha_{\lambda}^{c} e(\theta)}\right) \mathrm{e}^{-2 \alpha_{\lambda}^{v} R_{f} \cos (\theta)}\right]+1-\mathrm{e}^{-\alpha_{\lambda}^{c} e(\theta)}\right) \mathrm{d} \lambda \mathrm{d} \theta }
\end{aligned}
$$




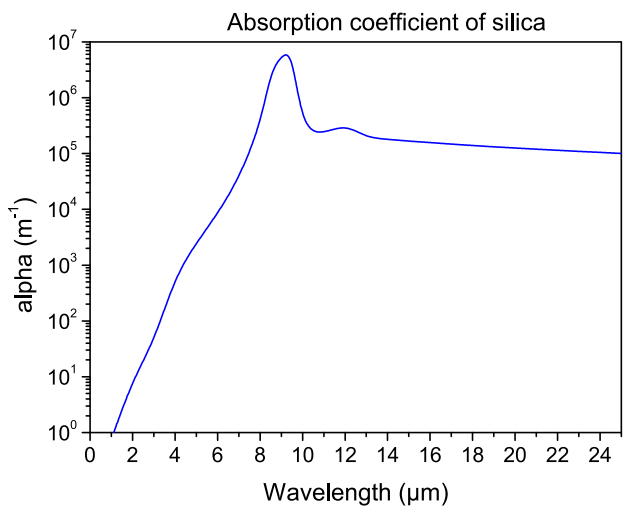

(a) Absorption

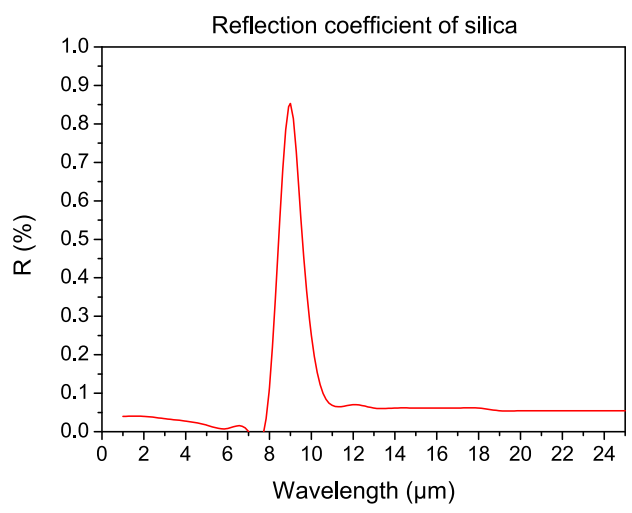

(b) Reflection

Fig. 11. Optical coefficients of silica

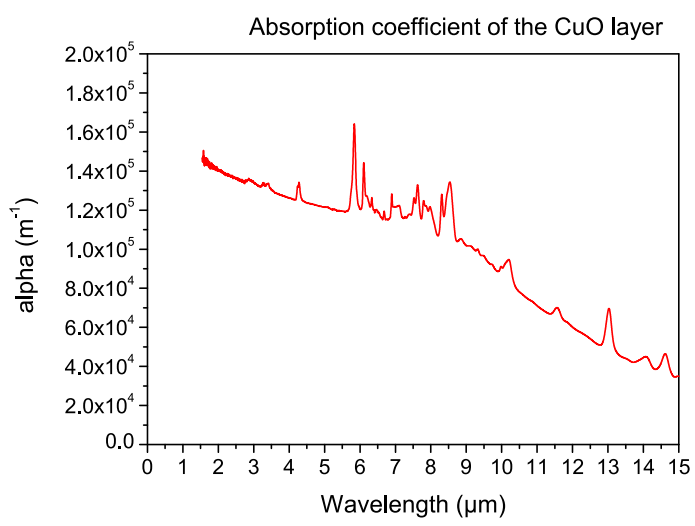

Fig. 12. Absorption coefficient of $\mathrm{CuO}$ in its polymer matrix.

where

- $\alpha_{\lambda}^{c}$ is the absorption coefficient of $\mathrm{CuO}$

- $\alpha_{\lambda}^{v}$ is the absorption coefficient of fused silica

- $f_{\lambda}$ is the incident spectral density and is proportional to $B_{\lambda, T}$ given by Planck's law (cf. Equation 1)

- $f$ is the total incident spectral density $f=\int_{\lambda=0}^{\lambda=\infty} f_{\lambda} \mathrm{d} \lambda$

- $e(\theta)$ is the effective thickness defined by:

$$
e(\theta)=\sqrt{\left(R_{f}+e_{\mathrm{CuO}}\right)^{2}-R_{f}^{2} \sin ^{2} \theta}-R_{f}^{2} \cos \theta
$$

This equation represents the projection of the thickness of the coating for an angle $\theta$. The part $H$ corresponding to the heads must be added. 


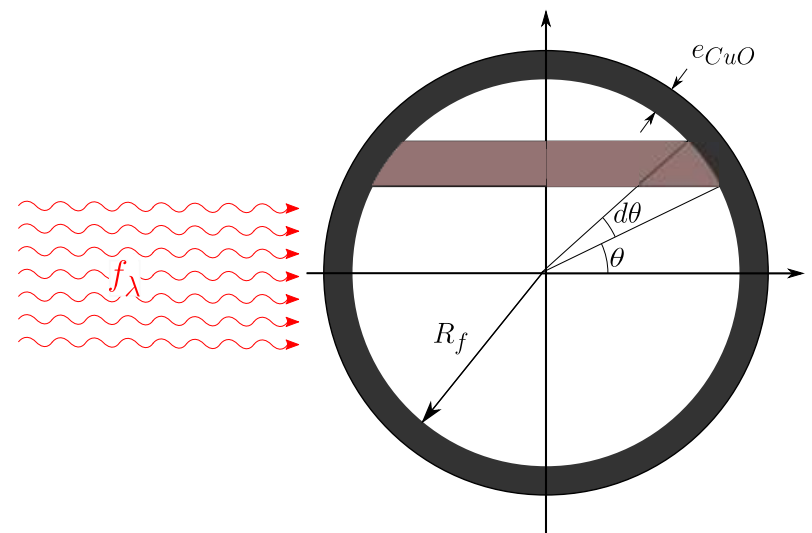

Fig. 13. Scheme for the computation of the fiber absorption.

If $R_{s}=R_{f}+e_{\mathrm{CuO}}$ and $\theta^{*}=\arcsin \frac{R_{f}}{R_{s}}$

$$
H=2 R_{S} L \int_{\lambda=0}^{\lambda=\infty} \int_{\theta=\theta^{*}}^{\theta=\frac{\pi}{2}}\left(1-\mathrm{e}^{-2 \alpha_{\lambda}^{c} R_{s} \cos \theta}\right) \frac{f_{\lambda}}{f} \cos \theta \mathrm{d} \theta \mathrm{d} \lambda
$$

The total absorption coefficient of the fiber becomes:

$$
\begin{aligned}
K_{\mathrm{abs}}=\frac{R_{f}}{R_{s}} \int_{\lambda=0}^{\lambda=\infty} \int_{\theta=-\frac{\pi}{2}}^{\theta=\frac{\pi}{2}} \cos (\theta) \frac{f_{\lambda}}{f} & \\
\left(\mathrm { e } ^ { - \alpha _ { \lambda } ^ { c } \cdot e ( \theta ) } \left[1-\mathrm{e}^{-2 \alpha_{\lambda}^{v} \cdot R_{f} \cos (\theta)}+\right.\right. & \left.\left.\left(1-\mathrm{e}^{-\alpha_{\lambda}^{c} e(\theta)}\right) \mathrm{e}^{-2 \alpha_{\lambda}^{v} \cdot R_{f} \cos (\theta)}\right]+1-\mathrm{e}^{-\alpha_{\lambda}^{c} e(\theta)}\right) \mathrm{d} \lambda \mathrm{d} \theta \\
& +2 \int_{\lambda=0}^{\lambda=\infty} \int_{\theta=\theta^{*}}^{\theta=\frac{\pi}{2}}\left(1-\mathrm{e}^{-2 \alpha_{\lambda}^{c} R_{s} \cos \theta}\right) \frac{f_{\lambda}}{f} \cos \theta \mathrm{d} \theta \mathrm{d} \lambda
\end{aligned}
$$

\subsubsection{Convection losses}

The fiber exchanges heat with the ambient air by a natural convection mechanism. The convection losses are given by the classical Equation 15

$$
\Phi_{\mathrm{conv}}=K_{c} 2 \pi R_{s} L\left(T-T_{a}\right)
$$

where

- $K_{c}$ is the exchange coefficient with the fluid around the fiber (here = air)

- $R_{S}$ is the radius of the fiber with its coating

- $L$ is the exposed length

- $T$ is the temperature of the fiber (what is calculated)

- $T_{a}$ is the ambient temperature 
Due to the cylindrical geometry of the problem, $K_{c}$ is calculated using the adimensional Nüsselt number defined by :

$$
\mathrm{N} \ddot{\mathrm{u}}=\frac{K_{c} D}{\kappa}
$$

where

- $D$ is the diameter of the fiber with its coating $\left(D=2 R_{S}\right)$

- $\kappa$ is the thermal conductivity of the fluid (air here)

The Nüsselt number depends on the fluid properties (viscosity, thermal conductivity, density), on the geometry and on the type of convection mechanism (natural or forced). In this case, natural convection in air is considered and the fiber is a horizontal tube of diameter $D$ at uniform temperature in the considered zone. Under these conditions, the Nüsselt number is given by (Churchill, 1983; Padet, 2005) :

$$
\mathrm{Nü}=A \mathrm{Ra}^{n}
$$

where $A$ and $n$ are two empirical parameters and $\mathrm{Ra}$ is the Rayleigh number. It is the product of Grashof and Prandl numbers given by Equation 18 and Equation 19 respectively.

$$
\begin{gathered}
\mathrm{Gr}=\frac{g \beta D^{3} \Delta T}{v^{2}} \\
\operatorname{Pr}=\frac{v}{a}
\end{gathered}
$$

where

- $g$ is the acceleration of gravity in $\mathrm{m} / \mathrm{s}^{2}$

- $\beta$ is the buoyancy coefficient (for perfect gases $\beta=\frac{1}{T}$ ) in $\mathrm{K}^{-1}$

- $\Delta T$ is the temperature difference between the surface and the fluid in $\mathrm{K}$

- $a$ is the effusivity of air $\left(=\frac{\kappa}{\rho \mathrm{C}}\right)$ with $\kappa$ the thermal conductivity in $\mathrm{Wm}^{-1} \mathrm{~K}^{-1}, \rho$ the density in $\mathrm{kg} / \mathrm{m}^{3}$ and $C$ the specific heat in $\mathrm{Jkg}^{-1} \mathrm{~K}^{-1}$

- $v$ is the cinematic viscosity in $\mathrm{m}^{2} / \mathrm{s}\left(v_{\text {air }}=1.2 \times 10^{-5} \mathrm{~m}^{2} / \mathrm{s}\right)$

For gases, Pr is 0.7. Due to the fact that $n$ is small, the Nüsselt number will not vary a lot in the considered temperature range. In the range of fiber diameter used in this study, $\mathrm{Nu} \approx 0.6$. The order of magnitude of $K_{c}$ is $50 \mathrm{~W} /\left(\mathrm{m}^{2} \mathrm{~K}\right)$. Equation 17 is valid for $10^{-4}<\mathrm{Ra}<10^{-2}$.

$$
\mathrm{Ra}=\frac{g \beta D^{3} \Delta T}{a v}
$$

Replacing in Equation 17 the values of the physical constants for air taken at $T_{a}=20{ }^{\circ} \mathrm{C}$, this equation turns into Equation 21 in the range of diameters used in this study with $A=1.02$ and $n=0.148$. As $n$ is small, the temperature dependence on $N \ddot{u}$ is small and this coefficient is almost constant and so is coefficient $K_{c}$.

$$
\mathrm{Nü}=A\left(10^{8} D^{3} \Delta T\right)^{n}
$$




\subsubsection{Radiation losses}

The radiation losses with the ambient are given by Equation 22

$$
\Phi_{\mathrm{rad}}=\epsilon 2 \pi R_{s} L \sigma\left(T^{4}-T_{a}^{4}\right)
$$

where

- $R_{S}$ is the radius of the fiber with its coating

- $\epsilon$ is the emissivity of the surface of the material (here $\mathrm{CuO}$ or silica)

- $\sigma$ is Stefan's constant (according to Stefan's law of emission of hot bodies, $\sigma=$ $\left.5.67 \times 10^{-8} \mathrm{~W} /\left(\mathrm{m}^{2} \mathrm{~K}^{4}\right)\right)$

As the difference $T-T_{a}$ is generally small, Equation 22 can be linearized

$$
\Phi_{\mathrm{rad}}=\epsilon 2 \pi R_{s} L \sigma\left(T^{4}-T_{a}^{4}\right)=K_{r} 2 \pi R_{s} L\left(T-T_{a}\right)
$$

with

$$
K_{r}=\epsilon \sigma \frac{\left(T^{4}-T_{a}^{4}\right)}{\left(T-T_{a}\right)} \approx 4 \epsilon \sigma T_{a}^{3}
$$

The order of magnitude for $K_{r}$ is $8 \mathrm{~W} /\left(\mathrm{m}^{2} \mathrm{~K}\right)$.

\subsubsection{Conduction losses}

The losses due to the thermal conduction along the fiber are given by the following relationship:

$$
\Phi_{\text {cond }}=K_{l} 2 \pi R_{s}^{2}\left(T-T_{a}\right)
$$

$K_{l}$ is a coefficient relative to the conduction through the fiber along its axis. The conduction through the thin layer of absorbing material is neglected. $K_{l}$ can be calculated by assuming that the rest of the fiber behaves as 2 cylindrical winglets. The conductivity of silica is small and this term has little influence on the computed result $\left(K_{l} \approx 65 \mathrm{~W} /\left(\mathrm{m}^{2} \mathrm{~K}\right)\right)$.

Now that the different terms are detailed, the temperature of the fiber at equilibrium can be computed and by using equations 12,22 and 25, Equation 6 becomes:

$$
K_{a b s} R_{s} L f=K_{r} 2 \pi R_{s} L\left(T-T_{a}\right)+K_{c} 2 \pi R_{s} L\left(T-T_{a}\right)+K_{l} 2 \pi R_{s}^{2}\left(T-T_{a}\right)
$$

Or dividing by $R_{S} L$

$$
K_{a b s} f=2 \pi\left(K_{r}+K_{c}+K_{l}^{\prime}\right)\left(T-T_{a}\right)
$$

with $K_{l}^{\prime}=K_{l} \frac{R_{s}}{\mathrm{~L}}\left(\approx 0.5 \mathrm{~W} /\left(\mathrm{m}^{2} \mathrm{~K}\right)\right)$

The sensitivity $\Sigma_{T}$ is then given by Equation 28

$$
\Sigma_{T}=\frac{\left(T-T_{a}\right)}{f}=\frac{K_{\mathrm{abs}}}{2 \pi\left(K_{r}+K_{c}+K_{l}^{\prime}\right)}
$$

$K_{\text {abs }}$ may depend on the source temperature $T$ if the absorption depends on the wavelength. Notice that for large temperature variations (high radiation fluxes), $K_{c}$ and $K_{r}$ depend on temperature (increase with temperature) and the sensitivity is no longer constant. As in the ideal absorbing case $K_{\mathrm{abs}}=2$, this equation shows that the sensitivity depends essentially 
on the losses through the coefficients $K_{c}, K_{l}^{\prime}$ and $K_{r}$. As the length of the exposed zone plays only a role in the coefficient $K_{l}^{\prime}$ which is small compared to the other coefficients, it may be concluded that the length has very little influence on the sensitivity.

The model was compared to the experimental results. Figure 14 shows the calculated results compared to the experimental values of the fiber coated with $\mathrm{CuO}$ for different source temperatures. The model curve was obtained directly from the physical and spectral properties of the materials. The parameters used in the model are listed in table 2.

\begin{tabular}{|l|c|}
\hline Absorption coefficient of CuO coating & $\alpha_{\mathrm{CuO}}(\lambda)=\frac{1.5 \times 10^{8} \mathrm{e}^{-0.038 \lambda}}{1000+\left(\mathrm{e}^{\lambda}\right)^{0.5}}$ \\
\hline Absorption coefficient of fused silica & $\alpha_{v}(\lambda)=\frac{10^{5}}{1+\mathrm{e}^{-1.8(\lambda-7)}}$ \\
\hline Reflection coefficient of fused silica & $R_{v}(\lambda)=0.06+0.8 \mathrm{e}^{-\frac{(7-\lambda)^{2}}{0.8}}$ \\
\hline Thermal conductivity of air & $\kappa_{\text {air }}=0.024+7 \times 10^{-5}\left(T_{a}-273.15\right)$ \\
\hline Emissivity of CuO coating & $\epsilon_{\mathrm{CuO}}=0.78$ \\
\hline Emissivity of glass & $\epsilon_{\text {glass }}=0.94$ \\
\hline Radius of the fiber & $R_{f}=62.5 \mu \mathrm{m}$ \\
\hline Thickness of CuO coating & $e_{\mathrm{CuO}}=40 \mu \mathrm{m}$ \\
\hline Room temperature & $T_{a}=293 \mathrm{~K}$ \\
\hline Nüsselt number & $\mathrm{Nü}=1.02\left(8 \times 10^{8} R_{s}^{3} \Delta T\right)^{0.148}$ \\
\hline$\Delta T$ used for the Rayleigh number & $\Delta T=1 \mathrm{~K}$ \\
\hline Conductivity along the fiber & $K_{l}=65 \mathrm{~W} /\left(\mathrm{m}^{2} \mathrm{~K}\right)$ \\
\hline Exposed length & $L=1 \mathrm{~cm}$ \\
\hline
\end{tabular}

Table 2. Table of parameters injected into the model

The obtained results confirm that the model fits reasonably well with the experimental data. Small discrepancies are attributed to the fact that, during the measurements, the source temperature varies with $\pm 5{ }^{\circ} \mathrm{C}$ and the sensitivity of the sensor is measured with $\pm 5 \%$ relative error.

\subsection{Case 2: fiber with absorbing coating and capillary}

As explained in section 4, the sensitivity of the sensor can be improved by protecting the fiber with a glass capillary. This case can be modeled and the model is explained in the next paragraph.

The structure is schematically represented in Figure 15.

The fiber and the capillary may both be covered with an absorbing coating or not. The system is more complicated and different energy exchanges take place through 3 surfaces:

- surface $1\left(S_{1}\right)$ of the fiber covered with the absorbing coating at temperature $T_{1}$ 


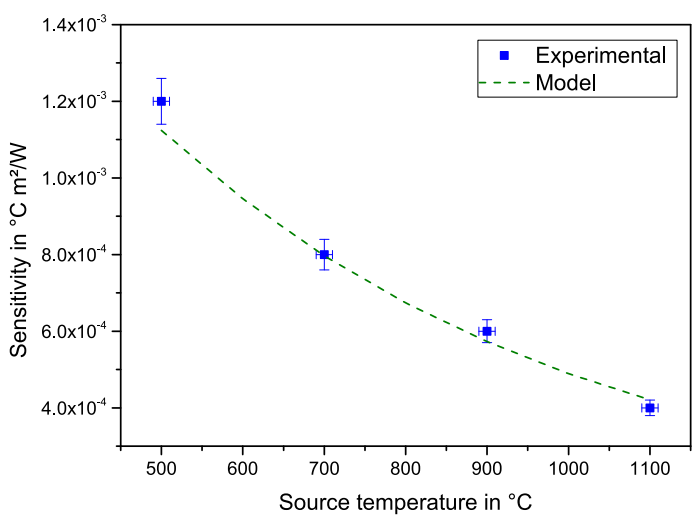

Fig. 14. Sensitivity $\Sigma_{T}$ of the bolometer for different source temperatures (solid line $=$ model, dots $=$ experimental results).

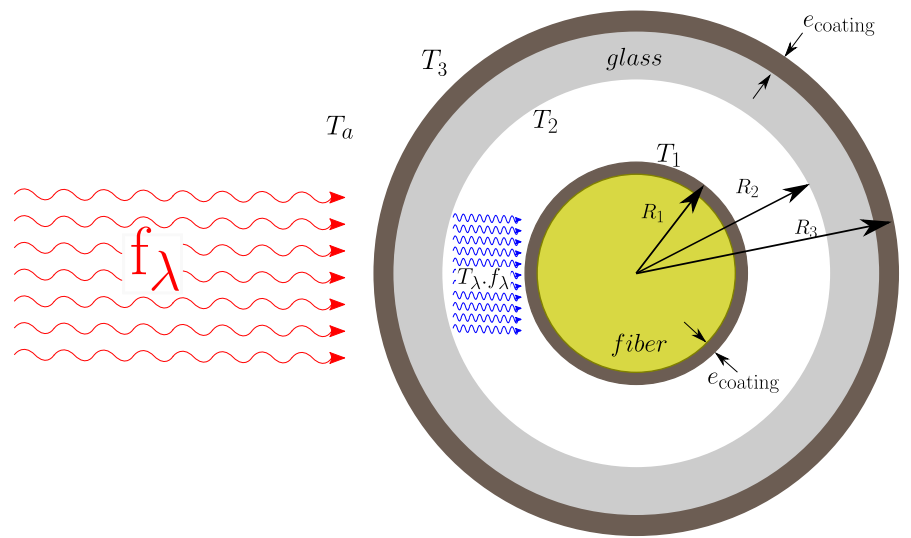

Fig. 15. Scheme of the fiber with a capillary.

- surface $2\left(S_{2}\right)$ at temperature $T_{2}$ inside surface of the capillary

- surface $3\left(S_{3}\right)$ at temperature $T_{3}$ in contact with ambient air

Surface 1 will be the reference surface for the calculations $\left(R_{1}=R_{f}+e_{\text {coating }}\right)$.

The thickness of the capillary is small and the temperature gradient between the walls is weak, thus it is assumed that $T_{2}=T_{3}$.

Again, as developed in the previous paragraph, considering $L$ the length of the exposed zone of the fiber, the energy balance of the various elements of the sensor can be computed.

For $S_{1}$, the balance between the different energy fluxes can be expressed (Equation 29):

$$
\Phi_{\mathrm{abs}}^{f}=\Phi_{\mathrm{r} 12}+\Phi_{\mathrm{c} 12}+\Phi_{\text {long }}
$$

- $\Phi_{\text {abs }}^{f}$ is the absorbed energy after partial absorption by the fiber of the incident radiation through the capillary 
- $\Phi_{\mathrm{r} 12}$ is the exchange (loss) by radiation with surface $S_{2}$

- $\Phi_{\mathrm{c} 12}$ is the heat transfer by conduction through the filling gas with $S_{2}$

- $\Phi_{\text {long }}$ is the heat transfer by conduction along the fiber

For $S_{2}$, heat is exchanged by radiation with $S_{1}$ and by conduction through the filling gas. The heat is transferred by thermal conduction through the capillary to $S_{3}$.

$$
\Phi_{c 23}=\Phi_{\mathrm{r} 12}+\Phi_{\mathrm{c} 12}
$$

- $\Phi_{\mathrm{c} 23}$ is the heat transfer by conduction through the capillary with $S_{2}$

For $S_{3}$, the outer surface of the capillary, the energy balance may be expressed by Equation 31:

$$
\Phi_{\text {loss }}=\Phi_{\mathrm{c} 23}+\Phi_{\mathrm{abs}}^{c}
$$

- $\Phi_{\text {abs }}^{c}$ is the partial absorption of the incident flux by the capillary

- $\Phi_{\text {loss }}$ represents the losses with the ambient (conduction along the capillary is neglected) $\Phi_{\text {loss }}=\Phi_{\text {conv }_{\text {ext }}}+\Phi_{\text {rad }_{\text {ext }}}$

Then

$$
\Phi_{\mathrm{loss}}=\Phi_{\mathrm{r} 12}+\Phi_{\mathrm{abs}}^{c}+\Phi_{\mathrm{c} 12}
$$

\subsubsection{Absorption}

The absorbed energy by the fiber of the transmitted radiation through the capillary is given by Eq. 33 .

$$
\Phi_{\mathrm{abs}}^{f}=T_{c} K_{\mathrm{abs}}^{f} R_{1} f L
$$

where $T_{c}$ is the mean transmission coefficient of the capillary $K_{\text {abs }}^{f}$ is computed in the same way as explained in the first case but absorption of the capillary is taken into account now

$$
\begin{aligned}
T_{c} K_{\mathrm{abs}}^{f}=\frac{1}{f} \int_{\lambda=0}^{\lambda=\infty} \int_{\theta=-\frac{\pi}{2}}^{\theta=\frac{\pi}{2}}\left(1-R_{\lambda}^{v}\right) f_{\lambda}^{\prime}\left(1-\mathrm{e}^{-2 \alpha_{\lambda}^{v} e(\theta)}\right) \sqrt{1-\left(\frac{R_{f}}{R_{3}}\right)^{2} \sin ^{2} \theta \mathrm{d} \theta \mathrm{d} \lambda} \\
+2 \int_{\lambda=0}^{\lambda=\infty} \int_{\theta=\theta^{*}}^{\theta=\frac{\pi}{2}}\left(1-\mathrm{e}^{\left(-2 \alpha_{\lambda} R_{3} \cos \theta\right)}\right) f_{\lambda}^{\prime} \cos \theta \mathrm{d} \theta \mathrm{d} \lambda
\end{aligned}
$$

where $f_{\lambda}^{\prime}=T_{\lambda} \cdot f_{\lambda}$ with

$$
T_{\lambda}=\frac{\left(1-R_{\lambda}\right) \mathrm{e}^{-\left(\alpha_{\lambda}^{c} e_{\mathrm{CuO}}+\alpha_{\lambda}^{v} e_{\text {capillary }}\right)}}{1-R_{\lambda}^{2} \mathrm{e}^{-\left(\alpha_{\lambda}^{c} e_{\mathrm{CuO}}+\alpha_{\lambda}^{v} e_{\text {capillary }}\right)}}
$$

with $e_{\text {capillary }}=\frac{\text { outer diameter-inner diameter }}{2}$ and $\theta^{*}=\arcsin \frac{R_{2}}{R_{3}}$.

The curvature of the capillary is neglected because the fiber diameter is small in comparison with the capillary dimension.

In equation $35, R_{\lambda} \approx 0$ because the roughness of the $\mathrm{CuO}$ coating used is high. $K_{\text {abs }}^{c}$ is obtained using Equation 36

$$
\begin{aligned}
K_{\mathrm{abs}}^{c}=\frac{R_{3}}{R_{1}} \frac{1}{f} \int_{\lambda=0}^{\lambda=\infty} \int_{\theta=-\frac{\pi}{2}}^{\theta=\frac{\pi}{2}}\left(1-R_{\lambda}^{v}\right) & f_{\lambda}\left(1-\mathrm{e}^{-2 \alpha_{\lambda}^{v} e(\theta)}\right) \sqrt{1-\frac{R_{2}^{2}}{R_{3}} \sin ^{2} \theta d \theta d \lambda} \\
& +2 \int_{\lambda=0}^{\lambda=\infty} \int_{\theta=\theta^{*}}^{\theta=\frac{\pi}{2}}\left(1-\mathrm{e}^{\left(-2 \alpha_{\lambda}^{c} R_{3} \cos \theta\right)}\right) f_{\lambda} \cos \theta \mathrm{d} \theta \mathrm{d} \lambda
\end{aligned}
$$




\subsubsection{Convection losses with the ambient}

The capillary exchanges heat with the ambient air by a convection mechanism like already presented before. The losses are expressed by Equation 37.

$$
\Phi_{\operatorname{conv}_{\mathrm{ext}}}=K_{\mathcal{c}_{\mathrm{ext}}} 2 \pi R_{3} L\left(T_{3}-T_{a}\right)
$$

This term has the same meaning as in the first case and $K_{\mathcal{C}_{\mathrm{ext}}}$ is the exchange coefficient to be calculated with Nü using radius equal to $R_{3}$.

\subsubsection{Radiation losses with the ambient}

The radiation losses with the ambient can be calculated as in the first case following relation 38

$$
\Phi_{\mathrm{rad}_{\mathrm{ext}}}=K_{r_{\mathrm{ext}}} 2 \pi R_{3} L\left(T_{3}-T_{a}\right)
$$

with

$$
K_{r_{\mathrm{ext}}}=\epsilon \sigma \frac{\left(T^{4}-T_{a}^{4}\right)}{\left(T-T_{a}\right)} \approx 4 \epsilon . \sigma T_{a}^{3}
$$

This term has the same meaning as before and $K_{r_{e x t}}$ is the exchange coefficient to be calculated with radius $=R_{3}$ and $\epsilon=0.78$ for $\mathrm{CuO}$ or 0.94 for glass.

\subsubsection{Conduction losses along the fiber}

This term is the same as in the first case without the glass capillary (Eq. 25).

\subsubsection{Exchange by radiation between 1 and 2}

Surface 1 exchanges heat by radiation with surface 2 . The heat exchange between surface 1 and surface 2 is given by

$$
\Phi_{\mathrm{r}_{12}}=K_{\mathrm{r}_{12}} 2 \pi R_{1} L\left(T_{1}-T_{2}\right)
$$

$K_{\mathrm{r}_{12}}$ is given by the classical formula for radiation heat exchange between two coaxial cylinders

$$
\Phi_{\mathrm{r}_{12}}=\frac{2 \pi R_{1} L 4 \sigma\left(T_{1}^{4}-T_{2}^{4}\right)}{\frac{1}{\epsilon_{1}}+\frac{\rho_{2}}{\epsilon_{2}}\left(\frac{R_{1}}{R_{2}}\right)^{2}}
$$

or

$$
\Phi_{\mathrm{r}_{12}} \cong \frac{2 \pi R_{1} L 4 \sigma T_{1}^{3}\left(T_{1}-T_{2}\right)}{\frac{1}{\epsilon_{1}}+\frac{\rho_{2}}{\epsilon_{2}}\left(\frac{R_{1}}{R_{2}}\right)^{2}}
$$

where $\epsilon_{1}=\epsilon_{\mathrm{CuO}}$ and $\epsilon_{2}=\epsilon_{\text {glass }}$ and

$$
K_{\mathrm{r}_{12}}=\frac{4 \sigma T_{1}^{3}}{\frac{1}{\epsilon_{1}}+\frac{\rho_{2}}{\epsilon_{2}}\left(\frac{R_{1}}{R_{2}}\right)^{2}}
$$




\subsubsection{Exchange by conduction between 1 and 2}

Surfaces 1 and 2 exchange heat through the filling gas. As the gap between the fiber and the capillary is small, no natural convection takes place and the heat transfer is a pure conductivity phenomenon. The conduction through the air layer is given by the classical relationship corresponding to the cylindrical geometry of the transfer:

$$
\Phi_{\mathrm{C}_{12}}=\frac{2 \pi \kappa L}{\ln \left(\frac{R_{2}}{R_{1}}\right)}\left(T_{1}-T_{2}\right)
$$

where $\kappa$ is the thermal conductivity of air.

$\mathrm{Or}$

with $K_{\mathrm{c}_{12}}=\frac{\kappa}{R_{1} \ln \frac{R_{2}}{R_{1}}}$

$$
\Phi_{\mathrm{c}_{12}}=K_{\mathrm{c}_{12}} 2 \pi R_{1} L\left(T_{1}-T_{2}\right)
$$

Using Equations 29 and 31 and assuming $T_{2}=T_{3}$, the following system of equations can be obtained:

$$
\begin{aligned}
& K_{\mathrm{abs}}^{f} R_{1} L T_{c} f=K_{\mathrm{r}_{12}} 2 \pi R_{1} L\left(T_{1}-T_{2}\right)+K_{\mathrm{c}_{12}} 2 \pi R_{1} L\left(T_{1}-T_{2}\right)+K_{l} 2 \pi R_{f}^{2}\left(T_{1}-T_{a}\right) \\
& K_{\mathrm{abs}}^{c} R_{3} L f+K_{\mathrm{r}_{12}} 2 \pi R_{1} L\left(T_{1}-T_{2}\right)+K_{\mathrm{c}_{12}} 2 \pi R_{1} L\left(T_{1}-T_{2}\right)=2 \pi R_{3} L\left(K_{\mathrm{c}_{\mathrm{ext}}}+K_{\mathrm{r}_{\mathrm{ext}}}\right)\left(T_{3}-T_{a}\right)
\end{aligned}
$$

The solution of this system of equations gives the temperature of the fiber $T_{1}$ and from this, the sensitivity $\Sigma_{T}$ can be calculated:

$$
\begin{aligned}
\Sigma_{T}= & \frac{\left(T_{1}-T_{a}\right)}{f} \\
& =\frac{\left[\left(K_{\mathrm{r}_{12}}+K_{\mathrm{c}_{12}}\right) \frac{R_{1}}{R_{3}}+\left(K_{\mathrm{c}_{\mathrm{ext}}}+K_{\mathrm{r}_{\mathrm{ext}}}\right)\right] T_{c} K_{\mathrm{abs}}^{f}+\left(K_{\mathrm{r}_{12}}+K_{\mathrm{c}_{12}}\right) K_{\mathrm{abs}}^{c}}{2 \pi\left[\left(K_{\mathrm{r}_{12}}+K_{\mathrm{c}_{12}}\right) \frac{R_{1}}{R_{3}}+\left(K_{\mathrm{c}_{\mathrm{ext}}}+K_{\mathrm{r}_{\mathrm{ext}}}\right)\right]\left(K_{\mathrm{r}_{12}}+K_{\mathrm{c}_{12}}+K_{l}^{\prime}\right)-2 \pi \frac{R_{1}}{R_{3}}\left(K_{\mathrm{r}_{12}}+K_{\mathrm{c}_{12}}\right)^{2}}
\end{aligned}
$$

As $K_{l}^{\prime}$ can be neglected, equation 47 becomes :

$$
\Sigma_{T}=\frac{\left[\frac{R_{1}}{R_{3}}+\frac{\left(K_{\mathrm{c}_{\mathrm{ext}}}+K_{\mathrm{r}_{\mathrm{ext}}}\right)}{\left(K_{\mathrm{r}_{12}}+K_{\mathrm{c}_{12}}\right)}\right] T K_{\mathrm{abs}}^{f}+K_{\mathrm{abs}}^{c}}{2 \pi\left(K_{\mathrm{c}_{\mathrm{ext}}}+K_{\mathrm{r}_{\mathrm{ext}}}\right)}
$$

Again, it is clearly put in evidence that the sensitivity depends essentially on the losses of the capillary with the ambient, the diameter of the fiber is of little importance. The most important parameter is the diameter of the capillary.

This model can now be confronted with experimental results. Fig. 16 and 17 show the comparison of the model and experimental data for different source temperatures and different capillary diameters. The values of the different parameters are given in table 2 .

Fiber protected by a capillary

The fiber is coated with $\mathrm{CuO}(44 \mu \mathrm{m})$ and surrounded by a glass capillary. The influence of the capillary diameter was experimentally tested and modeled as shown in Fig.16. The dots are the experimental points. 


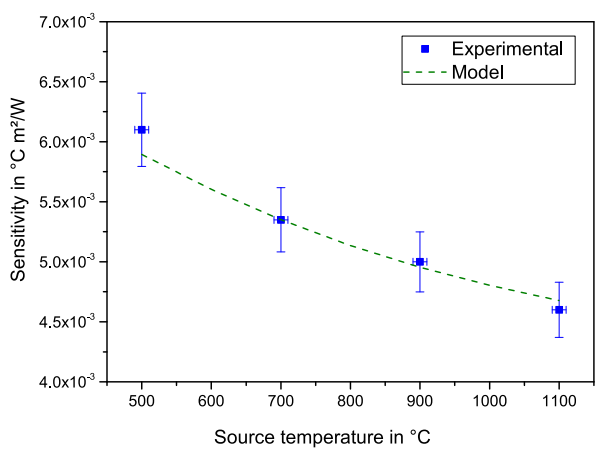

(a) Capillary 1 outer: 635 - inner: $560 \mu \mathrm{m}$

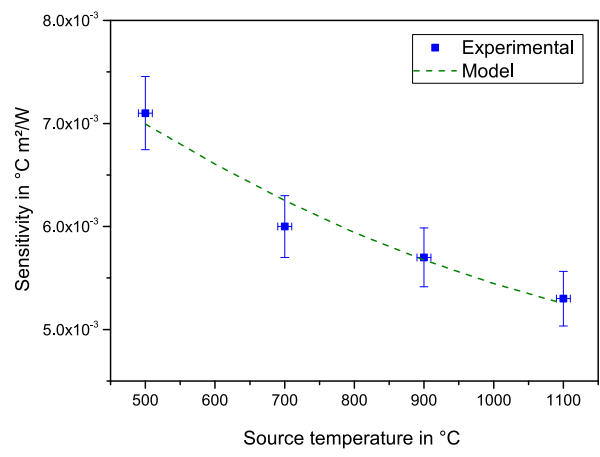

(b) Capillary 2 outer: 950 - inner: $750 \mu \mathrm{m}$

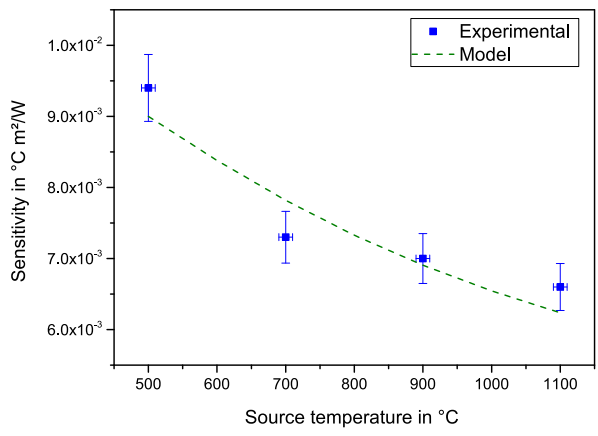

(c) Capillary 3 outer: 1900 - inner: $1660 \mu \mathrm{m}$

Fig. 16. Influence of the source temperature on the sensitivity of the sensor for a different capillary diameters.

Despite of the simplifications, the model predicts well the behavior of the sensor. These results show that the diameter of the capillary has a strong influence on the sensitivity of the system. In the following paragraph, the theoretical evolution of the sensor sensitivity as a function of the capillary diameter will be presented.

Fiber protected by a capillary covered with $\mathrm{CuO}$.

Fig. 17 shows the result of the modelling for the case when the capillary is covered with $\mathrm{CuO}$. The dots are the experimental points.

In fact, as the dimensions remain small, the exchanges between the capillary and the sensing fiber are very good and, as a consequence, the temperature at the surface of the fiber is close to the one at the surface of the capillary. The system behaves as if the diameter of the fiber was increased. The consequence is then a decrease in the convection losses $\left(K_{c}\right.$ decreases with increasing diameter) and thus an increase in sensitivity. 


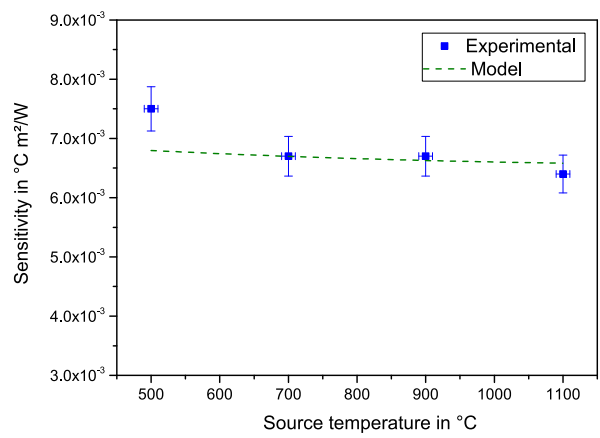

Fig. 17. Influence of the source temperature on the sensitivity of the sensor for a fiber protected by a capillary coated with $\mathrm{CuO}$ (diameter outer: 635 - inner: $560 \mu \mathrm{m}$ ).

\subsection{Limit cases}

The model can be predictively used to study the influence of some important parameters and limit cases. If the coating is perfectly absorbing, the sensitivity does not depend on the source temperature as it can be seen in Figure 18. In this example, the outer diameter of the capillary is $1000 \mu \mathrm{m}$ and inner diameter $800 \mu \mathrm{m}$. Thickness of the $\mathrm{CuO}$ layer is equal to $80 \mu \mathrm{m}$.

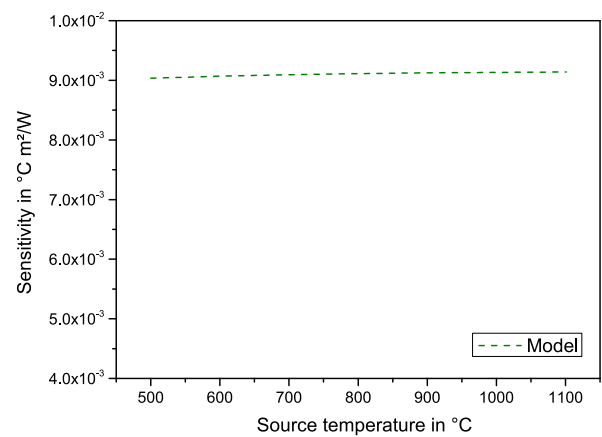

Fig. 18. Simulation of the source temperature dependence when the coating is perfectly absorbing.

The sensitivity is of the order of $9 \times 10^{-3}{ }^{\circ} \mathrm{C} /\left(\mathrm{W} / \mathrm{m}^{2}\right)$. As explained before, the outer diameter of the capillary is an important parameter. Fig. 19 shows the influence of the capillary diameter when the absorption is complete. The thickness of the capillary is kept at $200 \mu \mathrm{m}$. The point for diameter $=0$ means the fiber without capillary.

As expected, the increase of the diameter increases the sensitivity until a saturation is reached. It can be seen that using a capillary thicker than $5 \mathrm{~mm}$ is not interesting because the sensitivity is not substantially increased and the sensor becomes cumbersome which precisely reduces the advantage of using a fiber. The maximum sensitivity $\Sigma_{T}$ is about $2.5 \times 10^{-2}{ }^{\circ} \mathrm{C} /\left(\mathrm{W} / \mathrm{m}^{2}\right)$ or expressed in Bragg wavelength shift $\Sigma_{\lambda}=0.25 \mathrm{pm} /\left(\mathrm{W} / \mathrm{m}^{2}\right)$. This sensitivity is the maximum that could be reasonably expected for a sensor without concentrating packaging. 


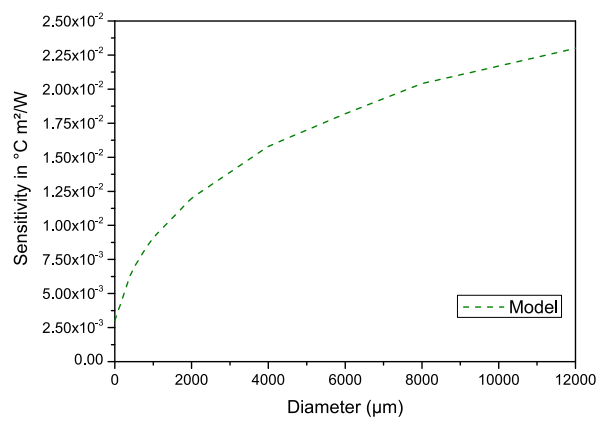

Fig. 19. Simulation of the capillary diameter dependence when the coating is perfectly absorbing.

\section{Conclusions}

In this chapter, a simple IR detection system with a pair of fiber Bragg gratings based on the working principle of the bolometer has been described. The sensor shows a linear behavior according to the flux intensity, a good sensitivity and a short response time (estimated to be less than $1 \mathrm{~s}$ ). The behavior of the sensor and its different configurations can be modeled and the predictions fit well the experimental results.

This kind of sensor possesses all the advantages of the optical fiber sensors : low weight, small size, immunity to electromagnetic interferences and remote operation. Indeed, quasi-distributed measurements based on this system can be made without difficulty using classical techniques (cascaded gratings, reflectometric techniques,...). The deposition method used here to coat the grating (encapsulation in a polymer matrix) requires only a few minutes, is cheap, and easily scaled up for mass production, which is important for commercial use of this device.

One of the most important applications would be in the perspective of early fire detection. The simple design presented above is sufficient for the detection of car fires in tunnels because the combustion of hydrocarbons and polymers releases hundreds of $\mathrm{kW} / \mathrm{m}^{2}$ of heat and this sensor can easily detect a few $\mathrm{kW} / \mathrm{m}^{2}$. With dedicated packaging and a good equipment for the measurement of the Bragg wavelength, a lower threshold can be achieved. The temperature dependence can be explained by a non-uniform absorption on the whole infrared wavelength range. Considering emission spectra, it can be deduced that silica contributes a lot to the absorption at low temperature while copper oxide is not as efficient as expected for the wavelengths below $4 \mu \mathrm{m}$ and so the absorption is not complete. The model shows that a better sensitivity and a lower temperature dependence can be achieved using a better absorbing layer (increasing the thickness for example). A second observation is that the shielding with a capillary tube is very efficient (sensor sensitivity enhanced by 5 to 8 times). A glass capillary also reduces the sensitivity to air streams. Finally, the packaging increases the shift of the Bragg wavelength by a factor of 2 to 3 . This simple packaging is cylindric (simple commercial tube cover with aluminium) and is not optimal. Using a parabolic shape should result in a better focalization and, as a consequence, a still higher sensitivity. 


\section{Acknowledgments}

This study was performed in the framework of the Opti ${ }^{2}$ Mat project financially supported by the Wallonia in Belgium. C. Caucheteur is supported by the Fonds National de la Recherche Scientifique (F.R.S.-FNRS). The authors take part to the Attraction Pole Program IAP 6/10 (photonics@be) of the Belgian Science Policy.

\section{References}

Buric, M., Chen, K. P., Bhattarai, M., Swinehart, P. R. \& Maklad, M. (2007). Active Fiber Bragg Grating Hydrogen Sensors for All-Temperature Operation, IEEE Photonics Technology Letters 19(5): 255-257.

Caucheteur, C., Debliquy, M., Lahem, D. \& Megret, P. (2008). Hybrid fiber gratings coated with a catalytic sensitive layer for hydrogen sensing in air, Optics Express 16(21): 16854.

Caucheteur, C., R. J. D. M. M. P. (2010). Infrared radiation detection with matched fiber bragg gratings, IEEE Photonics Technology Letters 22(23): 1732-1734.

Churchill, S. (1983). Heat Exchanger Design Handbook, Hemisphere.

Corres, J. M., del Villar, I., Matias, I. R. \& Arregui, F. J. (2007). Fiber-optic pH-sensors in long-period fiber gratings using electrostatic self-assembly, Optics Letters 32(1): 29.

Crunelle, C., Wuilpart, M., Caucheteur, C. \& Mégret, P. (2009). Original interrogation system for quasi-distributed FBG-based temperature sensor with fast demodulation technique, Sensors and Actuators A: Physical 150(2): 192-198.

Davino, D., Visone, C., Ambrosino, C., Campopiano, S., Cusano, a. \& Cutolo, a. (2008). Compensation of hysteresis in magnetic field sensors employing Fiber Bragg Grating and magneto-elastic materials, Sensors and Actuators A: Physical 147(1): 127-136.

Desvignes, F. (1991). Rayonnements optiques : Radiometrie - Photometrie, Editions Masson.

Fernandez-Valdivielso, C., Matias, I. R. \& Arregui, F. J. (2002). Simultaneous measurement of strain and temperature using a fiber Bragg grating and a thermochromic material, 2002 15th Optical Fiber Sensors Conference Technical Digest. OFS 2002(Cat. No.02EX533) 101: 203-206.

Gaussorgues, G., Micheron, F. \& Pocholle, J. (1996). Détecteurs infrarouges, Techniques de l'Ingenieur; pp. 1-42.

Han, Y.-G. (2009). Directional bending sensor with temperature insensitivity using a sampled chirped fiber Bragg grating, Journal of Applied Physics 105(6): 063103.

Ho, H. (2002). A fiber Bragg grating sensor for static and dynamic measurands, Sensors and Actuators A: Physical 96(1): 21-24.

Kronenberg, P., Rastogi, P. K., Giaccari, P. \& Limberger, H. G. (2002). Relative humidity sensor with optical fiber Bragg gratings, Optics Letters 27(16): 1385.

Lu, P., Men, L. \& Chen, Q. (2008). Tuning the sensing responses of polymer-coated fiber Bragg gratings, Journal of Applied Physics 104(11): 116110.

Men, L., Lu, P. \& Chen, Q. (2008). A multiplexed fiber Bragg grating sensor for simultaneous salinity and temperature measurement, Journal of Applied Physics 103(5): 053107.

Othonos, A., K. K. (1999). Fiber Bragg gratings: fundamentals and applications in telecommunications and sensing, Artech House.

Padet, J. (2005). Techniques de l'Ingenieur BE8206.

Perry, R., G. D. (1984). Perry's Chemical Engineers' Handbook, 6th edition edn, Mc Graw Hill.

Renoirt, J.-M., C. C. M. P. D. M. (2010). Infrared radiation detector using a pair of fiber bragg gratings, Proceedings of SPIE - The International Society for Optical Engineering 7726. 
Sheng, H., Fu, M., Chen, T., Liu, W. \& Bor, S. (2004). A lateral pressure sensor using a fiber Bragg grating, IEEE PHOTONICS TECHNOLOGY LETTERS 16(4): 1146-1148.

Sivathanu, Y. (1997). Fire detection using time series analysis of source temperatures, Fire Safety Journal 29(4): 301-315.

Yang, M., Dai, J., Zhou, C. \& Jiang, D. (2009). Optical fiber magnetic field sensors with TbDyFe magnetostrictive thin films as sensing materials, OPTICS EXPRESS 17(23): 20777-20782.

Yeo, T., Sun, T., Grattan, K., Parry, D., Lade, R. \& Powell, B. (2005). Characterisation of a polymer-coated fibre Bragg grating sensor for relative humidity sensing, Sensors and Actuators B: Chemical 110(1): 148-156.

Yüksel, K, C. C. R. J. M. P. D. M. W. M. (2011). Infrared radiation detector interrogated by optical frequency domain reflectometer (ofdr), Optical Sensors, OSA Technical Digest (CD) (Optical Society of America, 2011) (SMB6). 


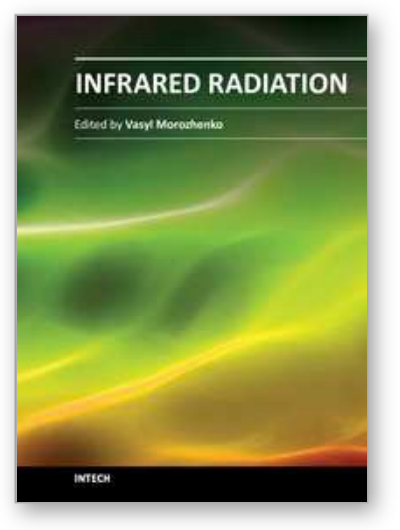

\author{
Infrared Radiation \\ Edited by Dr. Vasyl Morozhenko
}

ISBN 978-953-51-0060-7

Hard cover, 214 pages

Publisher InTech

Published online 10, February, 2012

Published in print edition February, 2012

This book represents a collection of scientific articles covering the field of infrared radiation. It offers extensive information about current scientific research and engineering developments in this area. Each chapter has been thoroughly revised and each represents significant contribution to the scientific community interested in this matter. Developers of infrared technique, technicians using infrared equipment and scientist that have interest in infrared radiation and its interaction with medium will comprise the main readership as they search for current studies on the use of infrared radiation. Moreover this book can be useful to students and postgraduates with appropriate specialty and also for multifunctional workers.

\title{
How to reference
}

In order to correctly reference this scholarly work, feel free to copy and paste the following:

Jean-Michel Renoirt, Christophe Caucheteur, Marjorie Olivier, Patrice Mégret and Marc Debliquy (2012). Infrared Radiation Detection Using Fiber Bragg Grating, Infrared Radiation, Dr. Vasyl Morozhenko (Ed.), ISBN: 978-953-51-0060-7, InTech, Available from: http://www.intechopen.com/books/infrared-radiation/infraredradiation-detection-using-fibre-bragg-grating

\section{INTECH}

open science | open minds

\section{InTech Europe}

University Campus STeP Ri Slavka Krautzeka 83/A 51000 Rijeka, Croatia Phone: +385 (51) 770447

Fax: +385 (51) 686166 www.intechopen.com

\section{InTech China}

Unit 405, Office Block, Hotel Equatorial Shanghai No.65, Yan An Road (West), Shanghai, 200040, China 中国上海市延安西路65号上海国际贵都大饭店办公楼 405 单元 Phone: +86-21-62489820

Fax: $+86-21-62489821$ 
(C) 2012 The Author(s). Licensee IntechOpen. This is an open access article distributed under the terms of the Creative Commons Attribution 3.0 License, which permits unrestricted use, distribution, and reproduction in any medium, provided the original work is properly cited. 